\title{
The interrelation of circulation processes in the atmosphere by $B$. L. Dzerdzeyevskiy with the change of runoff in the basins of rivers of South Kazakhstan
}

\author{
Aisulu Tursunova \\ Received: 27 May 2014/Accepted: 19 February 2015/Published online: 6 March 2015 \\ (C) The Author(s) 2015. This article is published with open access at Springerlink.com
}

\begin{abstract}
The article contains analysis of the interrelation of circulation processes in the atmosphere with the change of runoff in the basins of rivers. The results of estimates which show the relationship of circulation processes in the atmosphere with the runoff of the zone of formation of one of southern regions of Kazakhstan are discussed. The typification of circulation processes by B. L. Dzerdzeyevskiy and previously made estimates of water resources in the basins of rivers of South Kazakhstan were assumed as a basis. Certain areas were considered in this work: the Ile-Balkash basin, basin of rivers Shu-Talas and basin of the Syrdariya river, each basin is considered separately, since the runoff varies by regions and by the value of fluctuations, it is not permanent, because of the various factors of runoff formation in individual basins of that region. The calculations performed have shown the possibility of using typification of elementary circulation mechanism (ECM) for further researches of climatic changes, including to determine the direction of change of river runoff in other river basins. The created database on annual values of each of the 41 types of ECM can be used in other studies as well.
\end{abstract}

Keywords Typification of circulation of the atmosphere by Dzerdzeyevskiy · Elementary circulation mechanism (ECM) - Water resources - The basin of river of South Kazakhstan

A. Tursunova $(\bowtie)$

Institute of Geography, Almaty, Kazakhstan

e-mail: ais.tursun@bk.ru

\section{Introduction}

The cyclonic and anticyclonic activity of the atmosphere is the main factor determining the state and changeability of weather on the earth. The most dynamic are circulation factors, that cause transfer of large masses of atmospheric air formed over world ocean and land, as well as between certain climatic zones of the earth. There is a number of typifications of circulation processes and methods of their estimation, suggested by G. Ya. Vangengeim, A. A. Girs, M. Kh. Baidal and others at various times.

Typification of circulation of the atmosphere of the Northern Hemisphere by B. L. Dzedzeyevskiy was made on the basis of synoptic analysis of weather maps and baric topography of the Northern Hemisphere and considers the number and geographical location of the Arctic invasions (blocking processes) and outlets of southern cyclones. The presence of dynamic schemes of each elementary circulation mechanism, in short ECM, allows to determine what is the synoptic situation at each point of the Northern Hemisphere at this or another type of ECM (Dzerdzeyevskiy 1968, 1975).

In the typification of Dzerdzeyevskiy the terms "zonal" and "meridional" are used. Meridional are northern (movement of arctic anticyclones and distribution of their ridges to the south) and southern (movement of cyclones from low to high latitudes). Terms " latitudinal" and "longitudinal" are the analogs of these terms in relation to the sectors of the Hemisphere and their parts, i.e. all types of ECM, depending on the distribution are subdivided into respective groups.

According to the idea of Dzerdzeyevskiy, the important feature of typification is the state of the atmospheric circulation over the extra-tropical zone of the Northern Hemisphere that allows to track the movement of baric 
formations over certain areas and to monitor the change in temperature and air humidity (Dzerdzeyevskiy 1968, 1975).

Typification of Dzerdzeyevskiy was developed in the interiors of the Hydrometeorological service, the first work was published in the proceedings of the research institutions of the Hydrometeorological service in 1946, since 1955 the typification was developed in the Institute of Geography of the RAS (Dzerdzeyevskiy 1968, 1975; Zolotokrylin and Khmelevskaya (1999); Calendar of the consistent change of ECM 1987). According to this method, all the variety of circulation processes in the atmosphere of the Northern Hemisphere is divided into a finite number of ECM-elementary circulation mechanisms (total 41 types). ECM annually repeat themselves and alternate in a certain sequence due to seasonal weather changes. A calendar of ECM types is published (Calendar of the consistent change of ECM 1987), i.e. tables, according to which it is possible to estimate the frequency of repeatability of a particular type of ECM (in days) for each year.

Synoptic daily maps analyze allow to give off 41 ECM. They differ by direction and quantity of blocking and of southern cyclone outlets. It is important that ECM have season time. Each ECM has the cyclone and anticyclone trajectory scheme and description, maps of see level pressure and temperature, hay of AT 500 and temperature on AT 500 for 1970-1978, annual series and longtime series of fluctuation for 1899-1978. As a result, it is possible to obtain multi-year series of duration of the selected type of ECM, which can be analyzed using statistical methods that are usual for hydrologists and compare them with similar characteristics of river runoff. As we can see, the typification of ECMs by Dzerdzeyevskiy allows to obtain quantitative descriptions of atmosphere circulation, that advantageously distinguish it from the above mentioned existing methods of typification.

ECMs were been united in 4 groups, 13 types, 41 ECM. First group-zonal: 1-2 types, anticyclone on the North Pole, 2-4 of southern cyclone outlets in 2-4 sectors without blocking. Second group-zonal disturbance, types 3-7: high pressure on the Pole, one blocking over the Hemisphere. Third group-northern meridional, types 8-12: high pressure in the Arctic, 2-4 blocking and 2-4 southern cyclone outlets. Fourth group-southern meridional, type 13. Peculiarity of this group is cyclone circulation over the Arctic. It is result of cyclonic activity on arctic front especially regeneration of southern cyclones. Such processes have place at all seasons, but more often in summer. In winter 3 southern cyclone outlets take place over Hemisphere, in summer-4 outlets.

Designation ECM includes letters and numbers. The number indicates the type of ECM. The first letters of the alphabet (a, b, c, d ECM identifying differences within the same type in the directions of Arctic intrusions or southern cyclones. The letter "w"-winter and "s"-_ummerECM seasonal differences in the sign of the pressure fields over the oceans and continents. However, in the types of 4, 9 and 10 winter ECM (4a, 9b and 10a) the first letters of the alphabet.

\section{Special studies on testing of ECM}

Special studies on testing of ECM, which were performed by Dzerdzeyevskiy and researches from the Department of Climatology of the IG of the Russian Academy of Sciences and other independent specialists showed high effectiveness of using the proposed typification to describe quite a number of natural phenomena and the establishment of sufficiently reliable quantitative relationships between the components of the climate system (CCS). In the course of long-term works, performed by various research, extensive materials, which are partly placed on the site (www. atmospheric-circulation.ru), have been compiled; the original scientific results were obtained (list of scientific publications of 517 titles is placed on the same site).

In the territory of Kazakhstan, the typification of circulation processes by Dzerdzeyevskiy was used in the works of Akhmetova G. S. to identify their role in the change of air temperature over the Northern Hemisphere for the period from 1899 to 1987 (Akhmetova 2001); Eriskovskaya evaluated the influence of synoptic processes on the regime of precipitation and the changes in the mass balance of the Tuyyksu glacier (Eriskovskaya 2005). Also studies on the theoretical generalization and assessment of the reactions of the river runoff to change in the course of ECMs by Dzerdzeyevskiy in some river basins of Kazakhstan were carried out by us. (Tursunov and Tursunova 2005; Tursunova 2006). Previously, an independent analysis of the course of all 41 types of ECMs was conducted and some peculiarities of changes of them in recent years, were identified, which are reflected in the works in detail (Matskovskiy and Kononova 2011).

Out of the research (Matskovskiy and Kononova 2011) it follows that in the meridional group the meridional northern processes are currently rising, and the meridional southern ones are decreasing in duration. Figures 1, 2 shows an obvious representation of the course of meridional and zonal groups of ECM (www.atmosphericcirculation.ru).

Also a number of conclusions, which formed the basis of selection of runoff forming ECM was made by the authors of the research (Matskovskiy and Kononova 2011): (1) from 1986 to 1997 the duration of northern and southern meridional groups of circulation was approximately at the 
same level and significantly exceeded the duration of other groups, and southern meridional group was more than 3 times longer than average. Such situation meant an extreme instability of the atmospheric circulation, which has not been observed for the whole previous period; (2) since 1998 the duration of southern meridional processes started to decrease, and northern ones-to grow. In 2010 the total annual duration of northern meridional processes was 196 days, and meridional southern ones-77 days.

\section{The dependence of runoff from changes of circulation processes in the earth's atmosphere by Dzerdzeyevskiy}

In this study, experiments to confirm the hypothesis of the Professor Abay Tursunov about the dependence of runoff from changes of circulation processes in the earth's atmosphere by Dzerdzeyevskiy are being conducted.

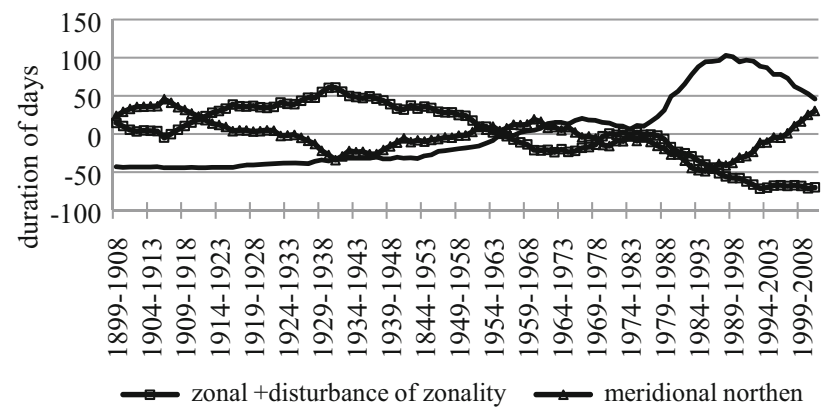

Fig. 1 Deviations of the total annual duration of the generalized zonal group from their long-term average values for the period of 1899-2010 (10-year sliding averages)
Out of 41 types of ECM we selected only those types of ECM, which, as it was presented, cause inflow of moist air to the south-west of Central Asia, form accumulation of precipitate and precipitation, and, as a result, affect the runoff, they are called "runoff-forming" ECM.

Certain areas were considered in this work: the IleBalkash basin, basin of rivers Shu-Talas and basin of the Syrdariya river, each basin is considered separately, since the runoff varies by regions and by the value of fluctuations, it is not permanent, because of the various factors of runoff formation in individual basins of that region.

The first object of the research were the left-bank tributaries of Ile river, as this area is the least affected by economic activity of the Ile-Balkash basin. Preliminary estimations to restore the runoff at individual posts were conducted earlier and the calculation of the main hydrological characteristics of the renewable water resources of the whole basin of the Ile river was made (Tursunov and Tursunova 2005; Tursunova 2006).

At the first stage an attempt to select various options of runoff forming ECM was made, dynamic schemes, annual and multi-year course of duration of effect (in days) of each type were carefully considered, and also an analysis of the literature sources in which an association of certain ECM with various natural phenomena was revealed. Calculations were made for the whole period of observation for the left bank tributaries of the Ile river from 1937 to 2000. In Table 1 all types of ECM, used in these options of selection, are presented. Calculations for determining the correlation coefficients were consolidated in Tables 2, 3 .

Determination of runoff forming types of ECM for the whole basin of the Ile river was made after careful analysis

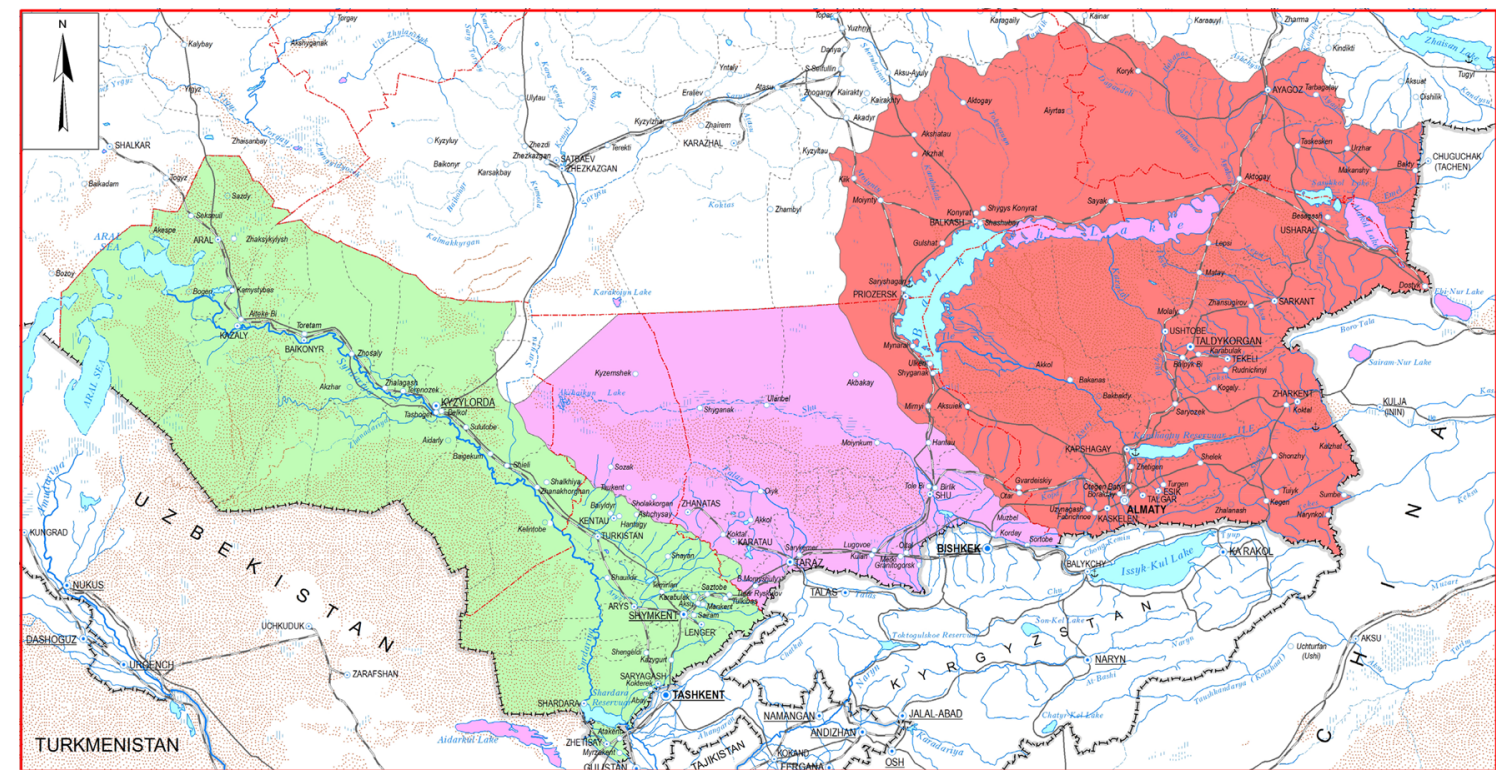

Fig. 2 Hydrographic scheme of river basins of South Kazakhstan 
Table 1 Types of ECM considered in the course of the experiment

\begin{tabular}{lcl}
\hline Option & Number of types & Types of ECM \\
\hline 1 (1937-2000), 6 (1975-2000) & 2 & $13 \mathrm{~s}, 13 \mathrm{w}$ \\
2 (1937-2000), 7 (1975-2000) & 22 & $\begin{array}{l}\text { 5a, 5b, 5c, 5d, 6, 7aw, 7bw, 8a, 8bw, 8dw, 8ds, 9a, 9b, 11a, 11b, 11c, 11d, 12bw, 12cw, } \\
12 \mathrm{~d}, 13 \mathrm{w}, 13 \mathrm{~s}\end{array}$ \\
$3(1937-2000), 8(1975-2000)$ & 20 & $\begin{array}{l}\text { 1a, 1b, 5a, 5b, 5c, 5d, 7aw, 7bw, 8a, 8bw, 8cw, 8dw, 11a, 11b, 11c, 12d, 12cw, 12bw, } \\
13 \mathrm{w}, 13 \mathrm{~s}\end{array}$ \\
$4(1937-2000), 9(1975-2000)$ & 11 & $7 \mathrm{aw}, 7 \mathrm{bw}, 8 \mathrm{bw}, 8 \mathrm{cw}, 8 \mathrm{dw}, 11 \mathrm{~d}, 11 \mathrm{c}, 12 \mathrm{bw}, 12 \mathrm{cw}, 13 \mathrm{w}, 13 \mathrm{~s}$ \\
$5(1937-2000), 10(1975-2000)$ & 13 & $4 \mathrm{~b}, 7 \mathrm{aw}, 8 \mathrm{a}, 9 \mathrm{a}, 10 \mathrm{a}, 11 \mathrm{a}, 11 \mathrm{~b}, 12 \mathrm{a}, 12 \mathrm{bw}, 12 \mathrm{cw}, 12 \mathrm{~d}, 13 \mathrm{w}, 13 \mathrm{~s}$ \\
$11(1975-2000)$ & 5 & $4 \mathrm{a}, 4 \mathrm{~b}, 8 \mathrm{bw}, 13 \mathrm{w}, 13 \mathrm{~s}$ \\
$12(1975-2000)$ & 8 & $8 \mathrm{cw}, 8 \mathrm{cs}, 8 \mathrm{dw}, 8 \mathrm{ds}, 10 \mathrm{a}, 10 \mathrm{~b}, 13 \mathrm{w}, 13 \mathrm{~s}$ \\
$13(1975-2000)$ & 8 & $1 \mathrm{~b}, 2 \mathrm{c}, 11 \mathrm{~d}, 12 \mathrm{a}, 12 \mathrm{bs}, 12 \mathrm{bs}, 13 \mathrm{w}, 13 \mathrm{~s}$ \\
\hline
\end{tabular}

Table 2 Coefficients of correlation of connection with of water runoff of the left bank tributaries of the Ile river and the sum of repeatability of various options of ECM (1937-2000)

\begin{tabular}{|c|c|c|c|c|c|c|c|c|c|c|c|}
\hline \multirow[t]{2}{*}{ Option of grouping of ECM } & \multicolumn{11}{|l|}{$\frac{\Delta \tau}{r}$} \\
\hline & 0 & 1 & 2 & 3 & 4 & 5 & 6 & 7 & 8 & 9 & 10 \\
\hline 1 & 0.46 & 0.5 & 0.5 & 0.44 & 0.39 & 0.32 & 0.25 & 0.16 & 0.09 & 0.04 & -0.1 \\
\hline 2 & 0.57 & 0.55 & 0.54 & 0.51 & 0.45 & 0.39 & 0.33 & 0.27 & 0.21 & 0.13 & 0.03 \\
\hline 3 & 0.63 & 0.63 & 0.61 & 0.58 & 0.53 & 0.46 & 0.38 & 0.32 & 0.23 & 0.12 & -0.01 \\
\hline 4 & 0.48 & 0.46 & 0.46 & 0.44 & 0.42 & 0.38 & 0.34 & 0.28 & 0.22 & 0.14 & 0.03 \\
\hline 5 & 0.38 & 0.41 & 0.46 & 0.46 & 0.49 & 0.47 & 0.43 & 0.36 & 0.29 & 0.22 & 0.13 \\
\hline
\end{tabular}

$\Delta \tau$ is the shear, in years

Table 3 The coefficients of correlation of connection $r$ with the shear $\Delta \tau$ of the sum of runoff of water of left bank tributaries of the Ile river and the sum of repeatability of various options of ECM (1975-2000)

\begin{tabular}{llllllll}
\hline Option of grouping of ECM & \multicolumn{1}{l}{$\frac{\Delta \tau}{r}$} & & & & \\
\cline { 2 - 7 } & 0 & 1 & 2 & 3 & 4 & 5 & 0.73 \\
\hline 7 & 0.89 & 0.89 & 0.87 & 0.81 & 0.66 & 0.60 \\
10 & 0.89 & 0.86 & 0.90 & 0.89 & 0.82 & 0.74 & 0.66 \\
13 & 0.83 & 0.87 & 0.89 & 0.87 & 0.83 & 0.76 \\
\hline
\end{tabular}

and study of each individual type of ECM: dynamic scheme Fig. 3 shows an example of one type of ECM.

It should be noted that all options included the 13 types of ECM as the total duration of their effect in days for a year is the longest, compared to other types, and a longterm variability is characterized by a sharp increase in the number of days. In 1998 the repeatability of ECM 131 was exactly 70 days (www.atmospheric-circulation.ru). As for the repeatability of ECM 13w in 1999 it reached 136 days. In the analysis of changes of 13-th types of ECM, their transfer into types of 11 and 8, which were also included into options of selection, are observed.

Study of dynamic schemes of types of 4, 5, 12 revealed that they cause the direct inflow of moist air exactly to the territory of Central Asia. As long as types of 2, 3, 6, some of the 1 and 10-th types are practically not active and little manifested in the annual course of the entire period of observation, they were not included into the major collections of options of ECM groups.

As a result of calculations a conclusion can be done that the comparison of repeatability of ECM and values of runoff of rivers of left bank tributaries of the Ile river for the entire period of instrumental observations (1937-2000) are slightly dependent on each other: Table 2 shows that correlation coefficients for this period are obtained as relatively small, maximum values do not exceed $0.48-0.63$.

Further the analysis was restricted only to the transgressive period of observation over the river runoff of the left-bank tributaries of the Ile river (1975-2000). Additional types of ECM, which gave the best results, were selected for comparison, and also three variants of groupings of types, options 11-13 ECM (Table 1). Study of 
dynamic schemes of additional types of 4, 5, 8, 12 revealed that these types of ECM cause the direct inflow of moist air to the territory of Central Asia and, therefore, influence precipitation and runoff; moreover the duration of effects of these types in days increases in the last decade. The conducted researches show that comparison of indices of circulation of Dzerdzeyevskiy with river runoff is possible only with joint grouping of ECM, i.e. there group influence take place.

According to the obtained sums of repeatability of days of ECM for the analysis 5-year average-outs were chosen and graphs of their long-term course, shown in Fig. 4 were made. In order to identify the availability and closeness of relations between the selected types of ECM and runoff of the left bank tributaries of the Ile river the coefficients of correlation with the same shear of $\Delta \tau$ were calculated; the results are put in Table 3 .

Table 3 shows that the maximum values of the correlation coefficient range from 0.89 to 0.90 , i.e. we can speak of an availability of a good connection between the runoff of left bank tributaries of the Ile river and the selected types of ECM. The highest correlation coefficients are obtained in the option (10) with the shear of 2 and 3 years, in option (7) with the shear of 1 year and in option (13) with the

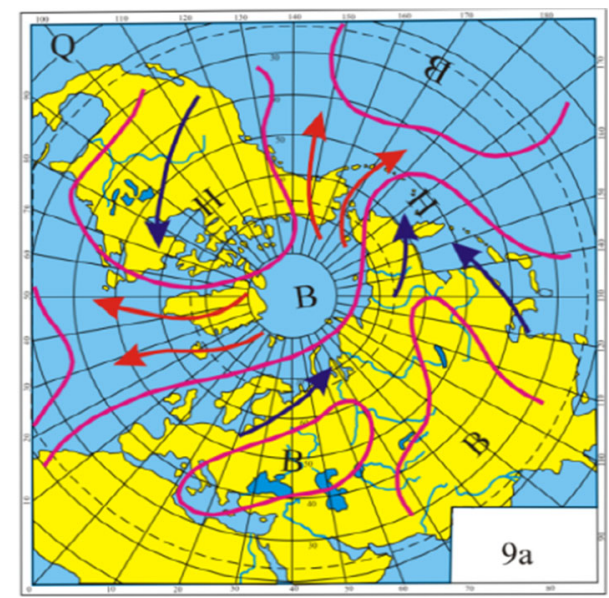

Fig. 3 Dynamic scheme where red arrows are the movement of anticyclones, and blue ones-of cyclones ECM 9a shear of 2 years. Calculations of coefficients were made on 5-year average-outs both for runoff and for duration (total days) of ECM.

Thus, a direct impact of ECM on the river runoff was revealed, that previously was expressed as a hypothesis based on general considerations; and also the data on water inflow to the zone of runoff formation of the left bank tributaries of the Ile river were considered. The calculated values of coefficients of correlation of connection range from 0.60 to 0.90 (for the period from 1975 to 2000), that indicates the availability of a good connection between runoff of water of the tributaries of the Ile river and the selected types of ECM.

The next considered basin of South Kazakhstan is the a basin of the Syrdariya river. Here some features that allow to select specific types of ECM for their grouping with each other, i.e. runoff-forming ECM, were identified. Type of ECM 4c cause inflow of cold air on the territory of Kazakhstan which follows from the consideration of its dynamic scheme (www.atmospheric-circulation.ru.) In aggregate, the duration of effect of types of $13 \mathrm{~s}$ and $13 \mathrm{w}$ reach significant values, starting since 1984: thus in 1989201 days, 1997 - 179 days, $2000-143$ days. Starting from the 1980s an increase in the duration of effect of types of 9a, $12 \mathrm{cw}, 6,11$-th types were observed.

The certain options of groupings of ECM with summing up of their repeatability for the entire period of observations from 1899 to 2006 were calculated, and also a 5-year averaging of all considered values was made. Twelve options of connection were calculated. Runoff in river basins of the basin of the Syrdariya river was estimated in the assessment of water resources for the period from 1928 and earlier till 2004. Some of the options of selection of groups of ECM are shown in Table 5, for all rivers of the basin of the Syrdariya river same groupings of ECM were taken.

Coefficients of correlation of connection of circulation processes in the atmosphere with rivers runoff range from -0.74 to 0.5 for the period of 1928-2004, and their higher rates of 0.96 are revealed for the period of 1980-2004. For the basin of the Arys river the coefficients of connection are considerably lower than for the basin of the Keles river. For the basin of the Keles river the higher correlation
Fig. 4 Progress of 5-year sliding: runoff of water of the left bank tributaries of the Ile river and total annual duration of ECM in days

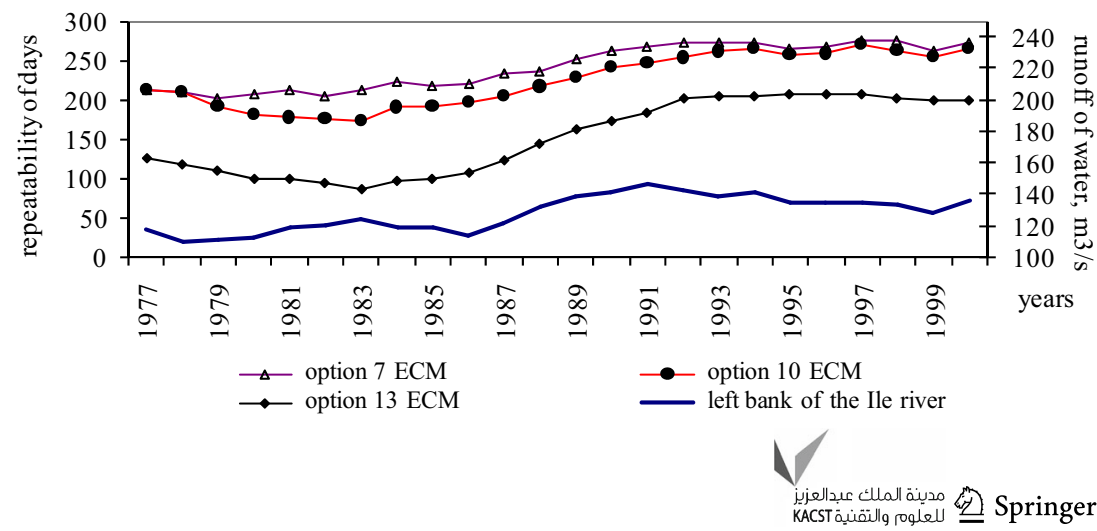


Table 4 Groupings of ECM types by Dzerdzeyevskiy for the basin of Syrdariya river and coefficients of correlation of connection of ECM groups and runoff in the basin of Keles river, connection is satisfactory

\begin{tabular}{llcrrr}
\hline Options & ECM types, included in the group & $1931-2004$ & $1950-2004$ & $1970-2004$ & $1980-2004$ \\
\hline 1 & 4v, 8gz, 11a, 11g & 0.10 & -0.20 & -0.42 & -0.28 \\
2 & 4v, 9a, 12a, 131, 13z & -0.19 & -0.05 & 0.72 \\
3 & 8gz, 11g, 11a, 12bz, 13z & -0.23 & 0.05 & 0.64 & $\mathbf{0 . 9 6}$ \\
4 & 6, 9a, 12a, 131 & -0.12 & -0.04 & $\mathbf{0 . 7 0}$ & $\mathbf{0 . 8 7}$ \\
\hline
\end{tabular}

Bolt font indicates that the values were obtained correlation coefficient, which may be used as an indicator of the closeness of the relationship between river flow and the elementary circulation mechanisms adopted in statistical calculations

Fig. 5 The graphs of connection of total annual duration (in days) of ECM and annual water expenditure for the basin of Syrdariya river

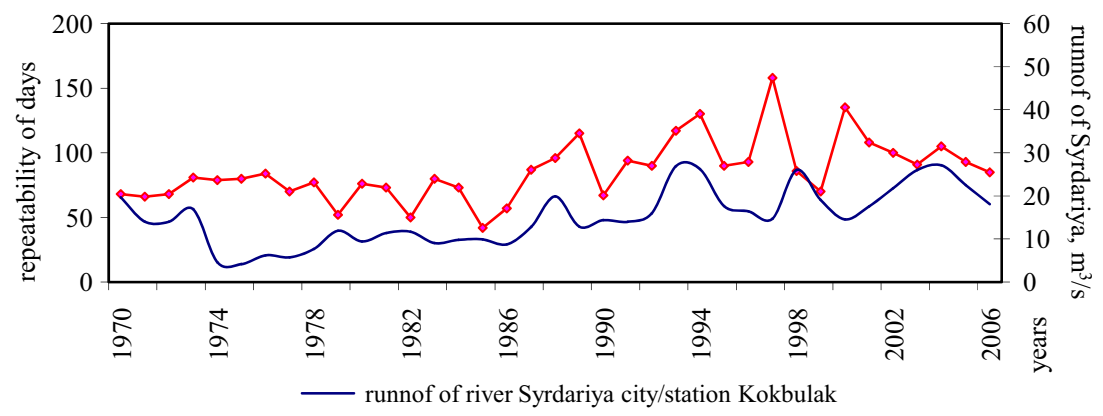

Table 5 Coefficient of correlation of connection of ECM groups and runoff in the basin of river Syrdariya

\begin{tabular}{|c|c|c|c|c|c|c|c|}
\hline \multirow[t]{2}{*}{ Options } & \multicolumn{4}{|c|}{ Kazaly, $181 \mathrm{~km}$ from the mouth } & \multicolumn{3}{|l|}{ City/station Kokbulak } \\
\hline & 1911-2004 & $1950-2004$ & 1970-2004 & 1980-2004 & 1970-2004 without averaging & 1970-2004 with 5-th averaging & 1980-2004 \\
\hline 1 & 0.52 & -0.16 & -0.23 & -0.27 & -0.19 & -0.40 & -0.25 \\
\hline 2 & -0.74 & -0.53 & 0.30 & 0.85 & 0.54 & 0.87 & 0.86 \\
\hline 3 & -0.16 & -0.41 & 0.51 & 0.90 & 0.43 & 0.86 & 0.90 \\
\hline 4 & -0.68 & -0.46 & 0.37 & 0.85 & 0.63 & 0.91 & 0.90 \\
\hline
\end{tabular}

Bolt font indicates that the values were obtained correlation coefficient, which may be used as an indicator of the closeness of the relationship between river flow and the elementary circulation mechanisms adopted in statistical calculations

coefficients of 0.96 are found for the period of 1980-2004 (Table 4). Coefficients of correlation of connection of ECM groups and runoff in the basin of the Arys river in most variants of calculations for the detection of connection did not give positive results, i.e. the highest connection coefficients are 0.68 .

Thus, analyzing the results of calculations (Fig. 5; Table 5), performed for all options of communication both for the basin of river Keles and for the basin of river Arys it can be possible to make the following conclusions: for the period from 1928 to 2004 only a visual connection is observed, and for the period from 1980 to 2004 also a quantitative connection of indices of circulation by typification of Dzerdzeyevskiy with runoff of the zone of formation in the basins of rivers Arys and Keles.

Also an experiment to detect the connection of ECM groups with runoff outside the zone of runoff formation was conducted in this research, and downstream the Syrdariya river in the station in $181 \mathrm{~km}$ from the mouth, cities of Kazaly and Kokbulak, i.e. in the over-regulated by the reservoir zone (Table 5). Results of calculations of Table 5 show, that distribution of correlation coefficients for the same options of ECM groupings gave better results compared to the results, obtained in the basins of Arys and Keles rivers.

With calculation according to option 1 the lowest correlation coefficients are observed, which can be seen on all the tables. We consider this is due to the lack of ECM groupings of 131 or $13 \mathrm{z}$ types in the option 1, the duration of effect of which for the last 50 years considerably increased. However, the results are more optimistic according to other options of calculations, which can be seen from Tables 5, 6 for all rivers and stations. Particularly the correlation coefficients are high in options 3 and 4, where such types as $6,9 \mathrm{a}, 11 \mathrm{e}$ and $13 \mathrm{~s}$ and $13 \mathrm{w}$ are included into the grouping.

Based on the analysis of the results of calculations (Fig. 5; Tables 4, 5), designed graphs of connection of 
runoff and ECM groupings for all options of river basins, the following conclusions can be done: from the period from 1928 to 2004 a visual connection is still observed, and for the period from 1980 to 2004 also a quantitative connection of atmospheric circulation by typification of Dzerdzeyevskiy with the runoff of the zone of formation in the basins of Keles and Arys rivers, as well as on Syrdariya river, is found.

From the experience of the previously conducted researches and from the present work it is found that with the lag of the runoff for 2-5 years relative to ECM the higher coefficients of connection are obtained. It is assumed that the good impact of circulation processes on the change of the runoff occurs within $2-5$ years, i.e. delays for 3 years on the average.

Also in these research a task of finding of a possible connection between the value of runoff for the basins of Shu and Talas rivers and the total annual duration of ECM (in days) was set. Water resources, i.e. runoff of the zone of formation of basins of Shu and Talas rivers were defined by traditional methods, adopted in hydrology. In addition to the data on the river runoff on the territory of Kazakhstan the data on hydrostations, located on the territory of Kyrgyzstan, are used.

Using the same techniques as for the considered above basins, works on groupings of ECM options for the basins of Shy and Talas rivers were carried out. In Table 6 some options for selecting ECM groups are presented. Figure 5

Table 6 Groupings of ECM types by Dzerdzeyevskiy for the basins of Shu and Talas rivers

\begin{tabular}{ll}
\hline $\begin{array}{l}\text { Options of } \\
\text { groupings }\end{array}$ & ECM types, included in the group \\
\hline 1 & $131,13 \mathrm{z}$ \\
2 & $4 \mathrm{a}, 4 \mathrm{v}, 8 \mathrm{bz}, 13 \mathrm{z}, 131$ \\
3 & $4 \mathrm{v}, 9 \mathrm{a}, 12 \mathrm{a}, 131,13 \mathrm{z}$ \\
4 & $7 \mathrm{az}, 7 \mathrm{bz}, 8 \mathrm{bz}, 8 \mathrm{vz}, 8 \mathrm{gz}, 11 \mathrm{~g}, 11 \mathrm{v}, 12 \mathrm{bz}, 12 \mathrm{vz}, 13 \mathrm{z}$, \\
& 131 \\
5 & $4 \mathrm{~b}, 7 \mathrm{az}, 8 \mathrm{a}, 9 \mathrm{a}, 10 \mathrm{a}, 11 \mathrm{a}, 11 \mathrm{~b}, 12 \mathrm{a}, 12 \mathrm{bz}, 12 \mathrm{vz}$, \\
& $12 \mathrm{~g}, 13 \mathrm{z}, 131$ \\
6 & $8 \mathrm{vz}, 8 \mathrm{vl}, 8 \mathrm{gz}, 8 \mathrm{gl}, 10 \mathrm{a}, 10 \mathrm{~b}, 13 \mathrm{z}, 131$ \\
7 & $1 \mathrm{~b}, 2 \mathrm{v}, 11 \mathrm{~g}, 12 \mathrm{a}, 12 \mathrm{bl}, 12 \mathrm{vl}, 13 \mathrm{z}, 131$ \\
\hline
\end{tabular}

shows graphs of the joint course of ECM options and runoff.

Some individual ECM groupings were calculated with summing of their repeatability for the whole period of observations from 1900 to 2006. In this case the calculations on 5-year averaging of the total duration of all ECM groups, as well as on the runoff of Shu and Talas rivers, were made, which was used in the previously conducted research. Fifteen options of connection were calculated. In the assessment of water resources the runoff in basins of Shu and Talas rivers was calculated for the period since 1930 and earlier, however the reliable series of water expenditure for many observation stations were not obtained, therefore we limited ourselves to the period from 1950 to 2002.

Coefficients of correlation of connection of circulation processes in the atmosphere with the rivers runoff range from -0.64 to 0.2 for the period from 1950 to 2002 , and their higher rates are again found in the period of 1980-2002 0.01-0.26. For the basin of river Shu, the obtained connection coefficients are considerably lower, than for the basin of the Talas river. With the lag of the series of runoff relative to ECM for 2-5 years for the period of observations from 1950 to 2002 sufficiently good (0.7-0.9) the connection coefficients were not available. It is assumed, that the influence of circulation processes on the change of characteristics of runoff again occurs within $2-5$ years, i.e. is delayed by an average of 3 years.

For the basin of river Talas the coefficients of correlation of connection range from -0.4 to 0.002 for the period of 1950-2002, higher coefficients of correlation are found in the period from 1980 to 2002, and they are large and high value: $0.81-0.91$.

Thus, based on the results of calculations (Fig. 6) designed for 15 options of connection both for the basin of Shu river and the basin of Talas river the following conclusions can be done: for the period from 1950 to 2002 only visual connection is observed, and for the period from 1980 to 2002 also a quantitative connection of the indices of circulation on typification by Dzerdzeyevskiy with the runoff of zone of formation in the basins of rivers Shu and Talas is found.
Fig. 6 Graphs of connection of 5 -year average-outs of total annual duration of ECM and annual expenditure of water for the basin of Shu and Talas rivers

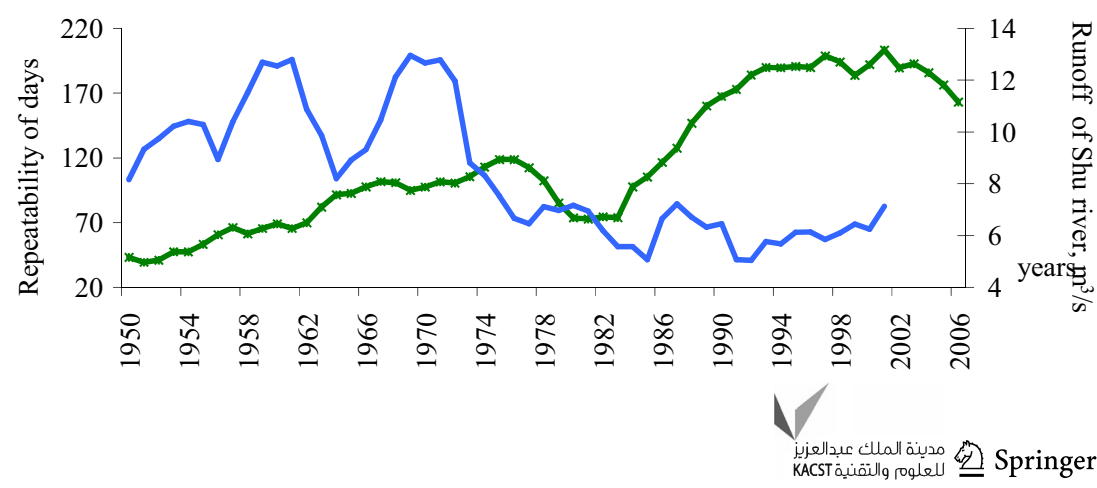




\section{Conclusion}

The obtained results are not very satisfactory and the further search of options of groups and analysis of ECM types will possibly allow to reveal a closer connection between runoff of the Shu and Talas rivers and ECM by Dzerdzeyevskiy.

Thus, analyzing the results of calculations, obtained for all basins of rivers of South Kazakhstan the following conclusions can be done:

1. For some basins a relation between runoff and options of ECM for the period of observations including from 1930 to 2006 is missing, but there is a visual connection, however a close and quantitative relation of indices of circulation by typification of Dzerdzeyevskiy with the runoff of zone of formation in basins of major rivers for the period from 1980 to 2006 is found.

2. It was found from the conducted researches on all river basins of South Kazakhstan that with the shear of runoff relative to the course of ECM options for 2-5 years there are higher coefficients of connection, that shows the influence of circulation processes on the change of characteristics of runoff, and this occurs within 2-5 years, i.e. it is delayed on an average of 3 years.

3. In addition, as it was mentioned earlier, types of circulation by Dzerdzeyevskiy characterize the situation of the whole Northern Hemisphere of the planet, and in this paper a small area of south-eastern Kazakhstan was selected for the experiment.

However, the calculations performed have shown the possibility of using typification of ECM for further researches of climatic changes, including to determine the direction of change of river runoff in other river basins. The created database on annual values of each of the 41 types of ECM can be used in other studies as well.
Open Access This article is distributed under the terms of the Creative Commons Attribution License which permits any use, distribution, and reproduction in any medium, provided the original author(s) and the source are credited.

\section{References}

Akhmetova GS (2001) The role of circulation conditions in the atmosphere in the change of temperature of air over Northern Hemisphere for the period from 1899 to 1987. Geography in Kazakhstan: results and ways of development. In: Collection of proceedings of the conference, Almaty Gylym, pp 97-101

Calendar of the consistent change of ECM for 87-year period (from 1899 to 1985) (1987) Inter-Departm Geophys. Committee of the AS of the USSR. In: Procedings of meteorological researches, No. 13, pp 29-116

Dzerdzeyevskiy BL (1968) Circulation mechanisms in the atmosphere of Norhern Hemisphere in XX century. Inter-Departm. Geophys. Committee of the AS of the USSR. In: Procedings of meteorological researches. M, p 240

Dzerdzeyevskiy BL (1975) General circulation of the atmosphere and climate. Selected works. M

Eriskovskaya LA (2005) Meteorological dependence of fluctuations of the border of feeding on the Tuyuksu glacier. Hydrometeorology and ecology. Almaty, No. 2, pp 79-88

Matskovskiy VV, Kononova NK (2011) Study of fluctuations of circulation of atmosphere of the Northern Hemisphere by the method of digital mapping. Izvestiya of the RAS, geographic series, No. 6, pp 100-114

Tursunov AA, Tursunova A (2005) Climate-driven changes of runoff of mountain rivers of basin of Balkhash lake. Scientific and technical news of STU of St. Petersburg. In: Proceedings of the international scientific-theoretical conference dedicated to the 100-the anniversary of R. R. Chugayev, St. Petersburg: Publishing house of the Polytechnic University, No. 1, pp 72-75

Tursunova AA (2006) Author's abstract of the Candidate's thesis. The current assessment of water resources of the basin of Ile river taking into account the circulation processes in the atmosphere. Almaty, p 22. www.atmospheric-circulation.ru

Zolotokrylin AN, Khmelevskaya LV (1999) Atmospheric circulation and precipitation in the Aral basin in the current century. In: Newsletter of the AS, series of geograph. Natural processes and dynamics of geosystems, M, No. 5, pp 30-33 